\begin{tabular}{|c|c|c|}
\hline Platinum & $193.4 \mathrm{I}$ & 194.89 \\
\hline Potassium $\ldots \ldots \ldots \ldots \ldots \ldots \ldots$ & 38.82 & 39. I I \\
\hline Praseodymium $\ldots \ldots \ldots \ldots \ldots \ldots \ldots$ & I 42.4 & 143.5 \\
\hline Rhodium $\ldots \ldots \ldots \ldots \ldots \ldots \ldots \ldots$ & $\mathrm{IO} 2.23$ & 103.01 \\
\hline 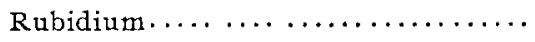 & $84 \cdot 7^{8}$ & 85.43 \\
\hline Ruthenium $\ldots \ldots \ldots \ldots \ldots \ldots \ldots$ & IOO.9I & 101.68 \\
\hline 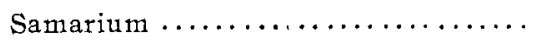 & 148.9 & 150.0 \\
\hline 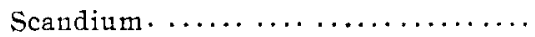 & $43 \cdot 7$ & 44.0 \\
\hline Selenium $\ldots \ldots \ldots \ldots \ldots \ldots \ldots \ldots$ & 78.4 & 79.0 \\
\hline 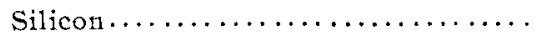 & 28.18 & 28.40 \\
\hline 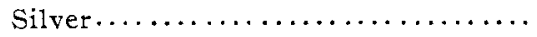 & IO7.II & 107.92 \\
\hline Sodium $\ldots \ldots \ldots \ldots \ldots \ldots \ldots \ldots \ldots$ & 22.88 & 23.05 \\
\hline 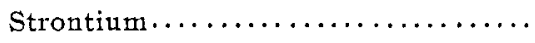 & 86.95 & $87.6 \mathrm{I}$ \\
\hline 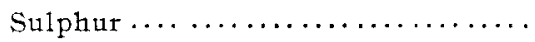 & $3 I .8_{3}$ & 32.07 \\
\hline Tantalum $\ldots \ldots \ldots \ldots \ldots \ldots \ldots \ldots$ & I $8 \mathrm{I} .2$ & I82.6 \\
\hline Tellurium $\ldots \ldots \ldots \ldots \ldots \ldots \ldots \ldots$ & 126.I? & $127.0 ?$ \\
\hline 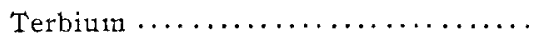 & $I_{5} 8.8$ & 160.0 \\
\hline 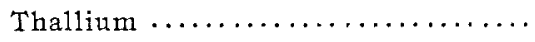 & 202.60 & 204.15 \\
\hline Thorium $\ldots \ldots \ldots \ldots \ldots \ldots \ldots$ & 230.87 & 232.63 \\
\hline Thulium $\ldots \ldots \ldots \ldots \ldots \ldots \ldots \ldots$ & 169.4 & 170.7 \\
\hline 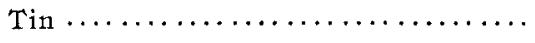 & I I8. I5 & I 19.05 \\
\hline Titanium $\ldots \ldots \ldots \ldots \ldots \ldots \ldots \ldots$ & 47.79 & 48.15 \\
\hline Tungsten $\ldots \ldots \ldots \ldots \ldots \ldots \ldots \ldots$ & I 83.44 & $\mathrm{r} 84.84$ \\
\hline Uranium $\ldots \ldots \ldots \ldots \ldots \ldots \ldots \ldots$ & $237 \cdot 77$ & 239.59 \\
\hline Vanadium $\ldots \ldots \ldots \ldots \ldots \ldots \ldots$ & 50.99 & 5 I 38 \\
\hline Ytterbium $\ldots \ldots \ldots \ldots \ldots \ldots \ldots$ & 171.7 & 173.0 \\
\hline Yttrium $\ldots \ldots \ldots \ldots \ldots \ldots \ldots \ldots$ & 88.28 & 88.95 \\
\hline Zinc $\ldots \ldots \ldots \ldots \ldots \ldots \ldots \ldots \ldots \ldots \ldots \ldots \ldots \ldots$ & $64.9 \mathrm{I}$ & $65.4 \mathrm{I}$ \\
\hline Zirconium $\ldots \ldots \ldots \ldots \ldots \ldots \ldots$ & 89.9 & 90.6 \\
\hline
\end{tabular}

\title{
COMPOSITION OF WOOD GUM.
}

By s. W. JOHNSON.

Receiver. January 20, I\&g6.

SINCE I879, when Thomsen published his investigation of $S$ "Wood Gum," the writer has, from time to time, as opportunity offered, employed several of the chemists of the Connecticut Agricultural Experiment Station in work upon the alkali-soluble carbohydrates of maize cobs, birch wood and vegetable ivory. This work has necessarily been subject to frequent and prolonged interruptions, and for that reason the publication of conclusive results has been greatly delayed.

Wood gum, which is abundantly extracted from the wood of deciduous trees by cold, weak (two to ten per cent.) solutions of 
sodium or potassium hydroxide, and thrown down therefrom by neutralization and by alcohol, has been analyzed by Thomsen, Koch, Schuppe and by Wheeler and Tollens. ${ }^{1}$

With exception of Schuppe, all these investigators obtained results on the whole agreeing fairly with the formula $\mathrm{C}_{8} \mathrm{H}_{10} \mathrm{O}_{5}$.

Schuppe's analyses mostly gave higher figures for carbon and hydrogen.

Xylan.-When it was shown by Wheeler and Tollens that xylose, the sugar first described by Koch, and obtained by him, from the products of the hydrolysis of wood gum, has the formula $\mathrm{C}_{5} \mathrm{H}_{10} \mathrm{O}_{5}$, it became extremely probable that the corresponding anhydride, now designated xylan, has the composition $\mathrm{C}_{6} \mathrm{H}_{8} \mathrm{O}_{4}$.

Analyses made in this laboratory in 1885 demonstrated that the cobs of Indian corn yield to five or ten per cent. potassium hydroxide solution, a body, which, precipitated by alcohol, acidulated with hydrochloric acid, suitably washed and thoroughly dried, has in fact the composition proper to pure xylan.

In 1880 xylan was thus prepared under my direction by Dr. Jenkins, as follows: Ground maize cob was digested for twentyfour hours with frequent agitation in a mixture of one volume of concentrated ammonia with seven volumes of water, the residue was washed on filters to remove all ammonia and digested forty-eight hours with seven per cent. caustic soda solution. The filtered extract was mixed with twice its volume of ninety-three per cent. alcohol. The precipitate was washed until the washings were neutral to test papers, then was stirred up with dilute hydrochloric acid, again washed with dilute alcohol until neutral and thereupon was further treated with absolute alcohol and ether and dried over sulphuric acid. About twenty-five per cent. of white, easily powdered material were thus obtained, which answered to Thomsen's description of wood gum.

It was not made blue by iodine solution. Agitated with pure water at common temperatures for a considerable time, it was taken up to the extent of o. I4 per cent., giving a neutral solution. Boiled for six hours with water, a neutralsolution resulted, which contained 0.44 per cent. of dissolved substance that very slightly reduced Fehling's solution. The solution in hot water wasunaf-

1 Ann. Chem. (Liebig) a54, 320 . 
fected by addition of normal lead acetate, but with basic lead acetate gave a heavy flocculent precipitate. Our earlier analyses of this substance gave varying results, due, it may be, partly to impurities, but doubtless largely attributable to its avidity for moisture and the difficulty of drying it completely or of holding it at a constant moisture content.

We could obtain no accordant analyses except by weighing off in quick succession several portions of the air-dry substance that had been fully exposed to air and was neither gaining nor losing moisture, determining carbon and hydrogen in some of these portions and moisture in others, with such precautions as to preclude change of water content.

Hygroscopic water we determined most satisfactorily by drying in vacuo at $\mathrm{I} 10^{\circ}-\mathrm{II} 2^{\circ} \mathrm{C}$. For this purpose the substance was contained in a stout glass tube about three $\mathrm{cm}$. wide and ten $\mathrm{cm}$. long, sealed off round at the base and narrowed above to a neck two $\mathrm{cm}$. wide. This was connected by a perforated cork with a water pump, giving a vacuum equal to twenty-eight to twentynine and one-half $\mathrm{cm}$. of mercury column, and was heated by placing within a close fitting vertical well, whose sides and bottom were surrounded by boiling aqueous solution of sodium nitrate contained in a closed copper box, the vapor from which was constantly returned by means of an efficient condenser. The glass drying tube, well corked, was counterpoised on the balance by a similar corked tube, and suitable precautions were used to avoid or compensate any changes of moisture of glass or corks.

Recurring to the already published statements, we note that the chemists whose analyses gave results mostly agreeing fairly with the formula $\mathrm{C}_{8} \mathrm{H}_{10} \mathrm{O}_{5}$ are silent (in the accounts I have been able to refer to) as to their mode of drying, so Thomsen and Koch, or as in case of Wheeler and Tollens, analyzed "substance that had been dried over sulphuric acid and warmed for some hours at $97^{\circ}$ in a water oven."

Mr. Winton, in this laboratory, found that two samples of finely subdivided air-dry wood gum from maize cobs required six days exposure to concentrated and recently boiled oil of vitriol to come to constant weight, with loss of 8 . Io per cent. and 
8. I I per cent., and thus dried further lost in three and one-half hours at $100^{\circ}$ in a current of dried hydrogen in one case 0.67 per cent., and in another 1.83 per cent., and on further heating in hydrogen for two hours at $120^{\circ}$, lost 0.07 and 0.25 per cent. respectively.

But while it may not be difficult to bring wood gum nearly to complete dryness in the water oven, it is not easy to weigh off, transfer to a combustion tube and burn this dried substance without its taking up sufficient moisture to vitiate an analysis, especially when the atmosphere is humid.

In I 880, Dr. Jenkins, following the methods then in use in this laboratory, made his first analyses of air-dry xylan, determining water by prolonged drying in a water oven. In three combustions he obtained, reckoned on dry matter, 45.25, 45.48 and $45.7^{2}$ per cent. of carbon respectively. His hydrogen determinations, however, were more irregular, viz.: $6.37,7.35$ and 5.90 per cent.

Dr. Jenkins next imperfectly dried his stock of xylan at $100^{\circ}$ and weighed off the portions for analysis as required. In four combustions, reckoned ash free, carbon ranged from 44.34 to 45.20 per cent., and hydrogen from 5.92 to 6.01 . His averages were: Carbon, 44.8I; hydrogen, 5.96. These results are quite like those from which Thomsen, Koch, and Wheeler and Tollens, deduced the formula $\mathrm{C}_{8} \mathrm{H}_{10} \mathrm{O}_{5}$.

Subsequently in 1883 , Mr. (now Professor) Milton Whitney, devoted considerable time to analyses of various preparations of wood gum, sometimes using air-dry material, atothers substance dried at $100^{\circ}$, but without reaching altogether satisfactory results.

Finally, after I, with Mr. Winton's aid, had accurately ascertained the conditions for completely desiccating this substance and the precautions needful in handling it, it became easy to fix its composition.

In I 885 Dr. Osborne made analyses of a sample of wood gum prepared by Mr. Whitney from corn cobs, being a first fraction thrown down by adding about one-half the amount of alcohol needful for complete precipitation of the soda-lye extract, and otherwise treated as before described. About two grams of this xylan required in one case near six hours heating at $112^{\circ}$ in a 
vacuum maintained at 29.0 to 29.5 inches mercury, and in another case when the vacuum ranged from 28.5 to 28.0 inches, needed nine hours heating at $112^{\circ}$ for reaching constant weights. In either case the loss was $13.5^{I}$ per cent., and further heating for three hours occasioned no change either in the weight or color of the substance.

Dr. Osborne's combustions of air-dry substance furnished results as follows:

\begin{tabular}{|c|c|c|c|c|}
\hline & I. & II. & III. & Average. \\
\hline Carbon & 39.12 & 39.10 & 39.06 & 39.09 \\
\hline Hydrogen............. & $6.8 \mathrm{r}$ & 6.65 & 6.73 & 6.73 \\
\hline 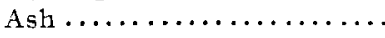 & 0.59 & 0.66 & 0.59 & 0.61 \\
\hline Moisture $\ldots \ldots \ldots \ldots$ & $\ldots$ & $\ldots$ & $\ldots$ & $13.5 \mathrm{I}$ \\
\hline
\end{tabular}

The above average reckoned on dry and ash-free substance is :

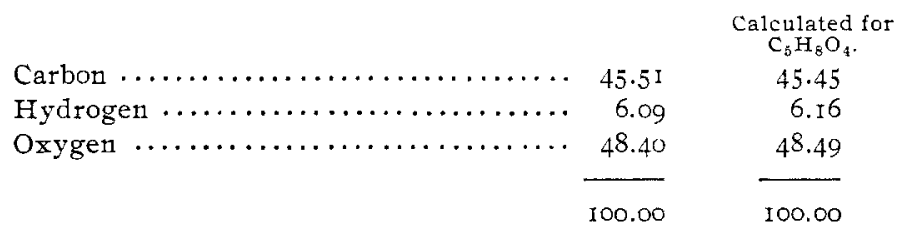

In another similar preparation Dr. Jenkins demonstrated the absence of nitrogen by soda lime combustion.

In two other preparations the ash contents were found to be respectively 0.23 and 1.73 per cent.

At my request Mr. E. B. Hurlburt has lately hydrolyzed corn cob xylan prepared in 1880 and obtained a syrup which, after seeding with a little pure xylose, ${ }^{1}$ in a few days, nearly solidified to a mass of crystals that when washed with alcohol and dried, melted at $153^{\circ} \mathrm{C}$.

It thus appears that the cobs of Indian corn yield very pure xylat1, $\mathrm{C}_{5} \mathrm{H}_{8} \mathrm{O}_{4}$.

It is also probable that many of the analyses of wood gum hitherto published, those of Schuppe possibly excepted were made on imperfectly dried material, and for that reason mainly, gave results leading to the incorrect formula $\mathrm{C}_{6} \mathrm{H}_{10} \mathrm{O}_{5}$.

Birch Wood Gum.-Preparations obtained from the wood of the American white, or gray birch, Betula alba, differ in compo-

${ }^{1}$ kindly supplied for this purpose by Prof. W. E. Stone, who was the first to announce the preparation of xylan and xylose from maize cobs. 
sition from the xylan of maize cob. Dr. Osborne found in the air-dry substance of one sample:

\begin{tabular}{|c|c|c|c|}
\hline & & II. & Average. \\
\hline Carb & 42.69 & 42.49 & 42.59 \\
\hline $1, \ldots . . .6 \ldots$ & 6.65 & 6.59 & 6.62 \\
\hline$\ldots \ldots \ldots \ldots$ & 0.65 & 0.64 & 0.65 \\
\hline$\ldots \ldots \ldots \ldots \ldots \ldots$ & $\ldots$ & $\ldots$ & 9.84 \\
\hline
\end{tabular}

Moisture was determined by drying in vacuo at II $2^{\circ} \mathrm{C}$. Constant weight was obtained in one determination in six hours with 29.5 inches of mercury in manometer, the loss being ro. 26 per cent., and in another in twelve hours with twenty-eight inches of mercury, the loss being 9.42 per cent.

The average results reckoned on substance free from moisture and ash are :

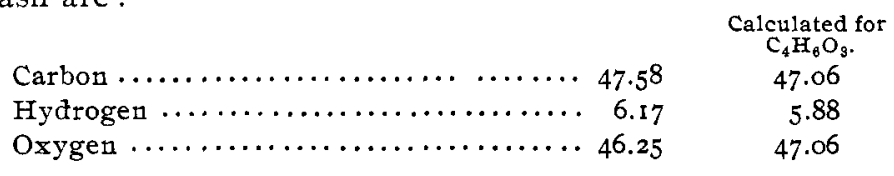

These figures for carbon are two per cent. higher than those belonging to the pentosans, and come nearer the composition of a tetrosan.

The birch wood gum, when hydrolyzed, yields a syrup from which, on long standing, or by fractioning with alcohol, a very small proportion of crystals may be separated, which do not appear to be increased in quantity by "seeding" with crystallized xylose.

The further study of birch wood gum and the products of its hydrolysis is reserved.

Mannan.-When the sugar obtained by Reiss ${ }^{1}$ from vegetable ivory, the fruit of Phytelephas, as the result of hydrolysis, was shown by E. Fischer to be mannose, it became evident that the substance yielding this sugar is a carbohydrate of composition corresponding to the formula $\mathrm{C}_{8} \mathrm{H}_{10} \mathrm{O}_{5}$.

According to Reiss, "vegetable ivory yields near seven and five-tenths per cent. of a water-soluble carbohydrate, which in the dry state is a yellowish brown gummy mass, having lefthanded polarization, readily hydrolyzed and then yielding the

1 Ber. d. chem. Ges., 22, 609.

2 Landwirthschaftliche Jahrbücher, $18,745,1889$. 
sugar mannose. The vegetable ivory also contains or yields, according to Reiss, a carbohydrate in large proportion, which he prepared as a white amorphous powder by digesting vegetable ivory shavings with an equal weight of seventy per cent. sulphuric acid for twenty-four hours, then adding to the mixture its weight of water, filtering, adding a little alcohol to throw down impurities, and lastly precipitating with mixed alcohol and ether, washing and drying the product. This substance, which Reiss found to swell and partially dissolve in water, and to be laevorotatory and to reduce Fehling's solution, was termed by him seminin and by Tollens' paramannan. It yielded mannose on hydrolysis, but its composition, so far as I am aware, has not been determined.

Several investigators have inferred the existence of mannan in seeds of coffee, date, nux vomica, Diospyros, cocoanut, and pine wood, etc., from the formation of an insoluble hydrazone in the products of the hydrolysis of these materials, but only Reiss, I believe, has attempted to separate the carbohydrate from the associated substances.

In the year I 880 a quantity of refuse vegetable ivory was sent to this station for examination, with the statement that "it had been used as feed for cattle, which ate it with great relish and fattened upon it.".

A "fodder analysis" was accordingly made, the results of which were as follows:

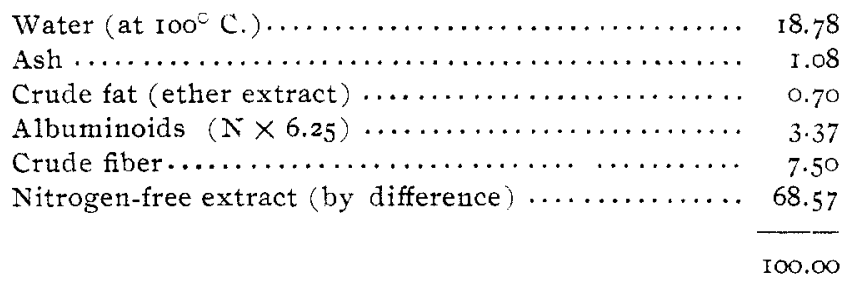

It was at the same time found that vegetable ivory yields to

1 Ladenburg's Handwörterbuch, 13, 755.

2 Loew and Ishii have recently stated that the root of Conophallas konnjaku, which is used as human food in Japan, contains mannan, i. e., yields mannosehydrazone in con. siderable quantity. (Versuchsstationen, 45,435.) Salep mucilage, formerly used as food for invalids, also very probably contains mannan or a manocellulose. (Gans and Tollens : Ann. Chem. (J,iebig), 249, 256.) 
soda lye a large proportion of substance resembling "wood gum," and a number of preparations were made in $\mathrm{I} 880$ by Dr. Armsby, and in 1883 by Mr. (now Professor) Milton Whitney.

Mr. Whitney also analyzed six of these preparations. His mode of drying was long exposure to concentrated sulphuric acid and subsequent heating for one hour in the water oven.

The results of these analyses were not altogether uniform, but either by excluding extremes or taking the average they fairly agreed with the formula $4\left(\mathrm{C}_{6} \mathrm{H}_{10} \mathrm{O}_{6}\right) \mathrm{H}_{2} \mathrm{O}$, which requires two and seven-tenths per cent. of hydrate water. This water, however, was doubtless merely hygroscopic.

After having ascertained the precise conditions for determining moisture in various specimens of wood gum, I requested Dr. Osborne in 1885 to analyze two of Dr. Armsby's vegetable ivory preparations then remaining. To determine moisture the airdry material was heated in vacuo (28.0 to 29.5 inches of mercury) at $\operatorname{II} 2^{\circ} \mathrm{C}$. for eight to nine hours to constant weight. In one case the substance was further heated for three hours without change in weight or appearance.

The combustions were made on portions of the same air-dry substance as served for estimating moisture.

The following are Dr. Osborne's results:

\begin{tabular}{|c|c|c|c|c|c|}
\hline \multicolumn{6}{|c|}{ SAMPLE B. I 2, AIR-DRY. } \\
\hline & I. & II. & III. & IV. & Average. \\
\hline Carbon.... & $\ldots$ & $\ldots$ & 40.08 & 40.17 & 40.13 \\
\hline Hydrogen.... & $\ldots$ & $\ldots$ & 6.82 & 6.82 & 6.82 \\
\hline Ash......... & $\ldots$ & $\ldots$ & 0.10 & 0.16 & 0.13 \\
\hline Moisture ........ & 9.59 & 9.65 & $\ldots$ & $\ldots$ & 9.62 \\
\hline
\end{tabular}

SAMPLE B. II. I, AIR-Dry.

\begin{tabular}{|c|c|c|c|c|c|}
\hline & I. & II. & III. & IV. & Average. \\
\hline art & $\ldots$ & $\ldots$ & 39.14 & 39.19 & 39.17 \\
\hline 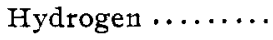 & $\ldots$ & $\ldots$ & 6.92 & 6.90 & $6.9 \mathrm{I}$ \\
\hline$\cdots$ & $\ldots$ & $\ldots$. & trace & trace & tra \\
\hline & 10.88 & I0. 88 & .... & .... & I0. 88 \\
\hline
\end{tabular}

The dry ash-free mannan has accordingly the subjoined composition : 


\begin{tabular}{|c|c|c|c|}
\hline & B. I. 2. & B. II. I. & $\begin{array}{l}\text { Calculated for } \\
\mathrm{C}_{6} \mathrm{H}_{10} \mathrm{O}_{5} \text {. }\end{array}$ \\
\hline Carbon $\ldots \ldots \ldots \ldots \ldots \ldots$ & 44.46 & 43.95 & 44.44 \\
\hline 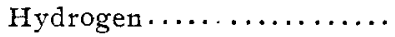 & 6.37 & 6.39 & 6.17 \\
\hline Oxygen...$\ldots \ldots \ldots \ldots$ & 49.17 & 49.66 & $49 \cdot 3^{8}$ \\
\hline & 100.00 & 100.00 & 100.00 \\
\hline
\end{tabular}

The mannan of vegetable ivory may be separated in fractions by adding alcohol to its solution in sodium hydroxide.

Armsby's preparation B. I. 2 and B. II. I were obtained as follows: One kilo of vegetable ivory turnings was digested for twenty-four hours in a mixture of $800 \mathrm{cc}$. concentrated a mmonia and five and a half liters of water and washed with water until ammonia was removed. The residue was digested twenty-four hours in a solution of 800 grams potassium hydroxide in eight liters of water and filtered, giving a first extract B. I. The undissolved substance was then treated for twenty-four hours with a solution of 480 grams potassium hydroxide in six liters of water and filtered. The second extract was marked B. II.

The potash extract $B$. I. was mixed with about three-sixteenths of its bulk of ninety-three per cent. alcohol, and allowed to stand an hour; the turbid liquid was separated from the precipitate by decantation and filtration. This first precipitate was B. I. I. The filtrate therefrom was completely precipitated by its own volume of alcohol, and the second precipitate was B. I. 2, whose analyses correspond so closely to $\mathrm{C}_{8} \mathrm{H}_{11} \mathrm{O}_{5}$.

The soda extract B. II. with rather more than one-fourth its bulk of alcohol gave B. II. I, (containing five-tenths per cent. less carbon than B. I. 2), and the filtrate therefrom with excess of alcohol yielded a second small precipitate B. II. 2.

These precipitations, after removing mother liquors, were washed with sixty-six per cent. alcohol until nearly neutral, then digested with excess of dilute hydrochloric acid for a day and finally washed out completely with sixty-six per cent., eighty per cent. and absolute alcohol and with ether in succession.

It thus appears that vegetable ivory may yield to dilute caustic alkali solutions a nearly or entirely pure mannan, and that this body is probably accompanied with an alkali-soluble substance of lower carbon content. 